4

\title{
Commentary
}

\section{Verticillium wilt of olive and its control: the heat is on}

\author{
Jesús Mercado-Blanco $^{1 *}$, F. Javier López-Escudero ${ }^{2}$
}

${ }^{1}$ Departamento de Protección de Cultivos, Instituto de Agricultura Sostenible, Consejo Superior de Investigaciones Científicas (CSIC), Apartado 4084, 14080

Córdoba, Spain.

2 Departamento de Agronomía, Universidad de Córdoba, Campus Universitario de Rabanales, Edificio Celestino Mutis (C4), 14071, Córdoba, Spain.

* Corresponding author: Jesús Mercado-Blanco, Departamento de Protección de Cultivos, Instituto de Agricultura Sostenible, Consejo Superior de Investigaciones Científicas (CSIC), Apartado 4084, 14080; e-mail: jesus.mercado@ias.csic.es; Tel: +34 957 499261; Fax: +34 957499252

Keywords integrated disease management, Olea europaea L., soil-borne pathogen, Verticillium dahliae 
Plant and Soil recently published a comprehensive and critical Marschner review about Verticillium wilt (López-Escudero and Mercado-Blanco 2011), one of the most threatening biotic constraints for olive (Olea europaea L.) production. The authors reviewed research efforts aimed to understand the diversity of the causal agent (the soilborne fungus Verticillium dahliae), the mechanisms underlying the interaction between the host plant and the pathogen, and the range of factors contributing to this disease becoming a major phytopathological problem in many traditional olive-growing areas. Since currently available measures to control Verticillium wilt of olive have proven ineffective when applied individually, an integrated management strategy is required to prevent significant economic losses, and more importantly, to avoid pathogen spread to new geographical areas where olive is increasingly being introduced (Tjamos 1993; Tjamos and Jiménez-Díaz 1998; López-Escudero and Mercado-Blanco 2011). Such a holistic strategy, encompassing biological, chemical, cultural and physical control measures, was presented and discussed as the only conceivable framework for an effective management of the disease.

Despite the indisputable historical and socio-economic importance of olives in specific geographical areas (i.e., the Mediterranean basin), and Verticillium wilt being a major threat to nurseries and to olive oil/table olive industries, this could be considered as a topic of regional interest, at least a priori. However, attention garnered by the review by López-Escudero and Mercado-Blanco (2011) has exceeded the authors’ expectations. During the first three months after publication (July-September 2011), the electronic version of the article was downloaded more than 1,000 times from the Plant and Soil web site. This confirms that the compilation effort was a worthy task, probably catching the attention of researchers in diverse fields such as soil microbiology, plant pathology, agronomy, epidemiology, molecular biology, etc., and by extension plant pathologists, olive farmers and researchers not directly involved in this pathosystem.

In addition, the authors' received comments from colleagues elsewhere require us to respond here. First, despite our extensive literature search, some references were inadvertently overlooked. For instance, Verticillium wilt of olive was reported in

63 Argentina by Docampo et al. (1981), an early report that was not detected in our survey.

64 This study is important because it documented the presence of the disease in olivegrowing areas of South America, and that it could probably be traced back as early as the 1950s, when a syndrome resembling Verticillium wilt was observed in olive trees

67 (Nicolini and Traversi 1950). Second, we failed to encounter the report on the detection 
of $V$. dahliae-infected olive trees in Montenegro (Latinovic and Vucinic 2010), a country that must be added to the list of places where the disease has been described suggesting that it is perhaps present in all areas where olive is cultivated. Finally, it is worth mentioning the important body of knowledge that Iranian researchers have gathered over the years on Verticillium wilt of olive. Some of their studies were opportunely mentioned in our paper, but others escaped our literature search. As extensive as the research on Verticillium wilt of olives in Iran, publications from these efforts are unavailable to wider research community because they are published in Farsi (Persian language) journals or books (for instance, Sanei et al. 2010). We thank colleagues who alerted us to this wider body of literature. Our literature survey focussed on broadly-accessible databases such as ISI web of Knowledge, SciVerse Scopus, with the exception of some references from national journals, meeting proceedings, or even $\mathrm{PhD}$ Theses, when they were thought to be essential for illustrating a specific comment. We obviously could not source research published in technical reports, meeting abstracts and research articles in local languages, etc. Nonetheless, we trust that most of the relevant, peer-reviewed, and easily-accessible reports and research articles were compiled in our appraisal.

Because of the alarming expansion of the disease, the heavy losses caused to this strategic commodity in the Mediterranean region, and the difficulties associated with controlling the pathogen have likely fuelled the number of studies and associated publications. Between the submission and publication of our review, a number of interesting papers were published that could not be cited. It is pertinent to briefly review some of them here since they enhance our understanding of the relevant aspects of the disease.

Lo Giudice et al. (2010) informed us that decline of young olive trees in Sicily is caused by simultaneous infections of $V$. dahliae and Phytophthora palmivora. The possible implications of synergistic interactions between diverse species of this Oomycete genus and $V$. dahliae were already highlighted (López-Escudero and Mercado-Blanco 2011). On the other hand, new epidemiological studies confirm that the most damaging $V$. dahliae pathotype (defoliating, highly virulent, belonging to vegetative compatibility group 1A [VCG1A]) is expanding alarmingly, and is clearly prevalent over other genetic and/or molecular groups of the pathogen in olive-growing areas in southern Spain (López-Escudero et al. 2010; Jiménez-Díaz et al. 2011). These surveys, and also that reported by Rodríguez et al. (2011), also provide interesting 
102 information on the correlation between several agronomical factors and the prevalence 103 of $V$. dahliae (or some of its pathogenic groups) in defined areas. They also demonstrate 104 that PCR-based tools are routinely and consistently used for the effective assignment of $105 V$. dahliae isolates to a given genetic (VCG) or pathogenic (pathotype) group. Available 106 molecular markers therefore provide useful epidemiological information along with 107 their diagnostic effectiveness. Maruthachalam et al. (2010) have also employed 108 molecular markers and PCR-based approaches to study molecular variation among $V$. 109 dahliae isolates, including some representatives from olive. Likewise, new molecular 110 markers (microsatellites and polymorphic sequences) have also been developed by 111 Berbegal et al. (2011). Despite these markers have been tested to analyze the genetic 112 diversity of potato and artichoke populations of $V$. dahliae, their application to other 113 hosts, including olive, is obviously feasible. Finally, from an epidemiological 114 perspective, Trapero et al. (2011) demonstrated that olive inflorescences can be 115 colonized by $V$. dahliae. Indeed, microsclerotia (survival structures which represent the 116 major infecting propagule of the pathogen in soils) were observed inside the peduncles. 117 Infected inflorescences which are easily decomposed in the soil after falling down can 118 act as an additional source of inoculum in Verticillium wilt epidemics.

119 Searching and exploiting sources of genetic resistance is one of the most 120 effective measures in an integrated disease management strategy (López-Escudero and 121 Mercado-Blanco 2011). Two Turkish groups have recently evaluated diverse olive 122 cultivars in relation to their resistance to $V$. dahliae. Sesli et al. (2010) found that all 123 cultivars examined in their study were susceptible to the pathogen. But a broader survey 124 involving more than 70 cultivars have yielded more promising results (Erten and Yildiz 125 2011). Despite the fact that most of the genotypes analyzed in their study were 126 extremely susceptible to the disease, 17 Turkish cultivars were found to be resistant or 127 highly resistant to a defoliating isolate of $V$. dahliae. Even though confirmation of these 128 results may need longer periods of evaluation, particularly under field conditions, 129 uncovering new sources of resistance offers a promising perspective for Verticillium 130 wilt resistance breeding programs.

131 The genetic and molecular basis of $V$. dahliae pathogenicity and virulence 132 remains largely unknown. However, a new phytotoxin (VdT) produced by an olive133 infecting isolate has been purified from cultures (Laoune et al. 2011). This phytotoxin 134 has been associated with disease symptoms in susceptible hosts. The authors claim that 135 VdT can be used to differentiate between Verticillium-tolerant and susceptible olive 
136 cultivars. A significant breakthrough will definitively help in shedding light to uncover pathogenicity traits of this vascular pathogen: the availability of the $V$. dahliae genome and that of its close relative V. albo-atrum (Klosterman et al. 2011). An important conclusion from this comparative genomics study, among others, is that both genomes encode more pectin-degrading enzymes and carbohydrate-active enzymes than other fungi, suggesting an unusual ability to degrade pectin barriers produced by the plant. There is no doubt that with this powerful tool in hand, new control strategies based on an in-depth knowledge of the pathogen genetics will be developed in the future.

Studies focussing on control strategies are few and far between and will need undoubtedly a long and arduous process to assess their effectiveness. This is particularly true for a pathosystem with very specific characteristics described in our review paper (López-Escudero and Mercado-Blanco 2011). However, a few studies to develop control measures have been published in the last few months. For instance, the potential use of composted olive mill wastes as fungicides against different pathogens, including V. dahliae, has been evaluated (Alfano et al. 2011; Yangui et al. 2010). Similarly, Arslan and Dervis (2010) have examined the antifungal activity of essential oils from different plant species against diverse $V$. dahliae vegetative compatibility groups. Interestingly, essential oils from some species proved to be natural fungicides effective against $V$. dahliae at relatively low concentration. However, these results will need further and prolonged evaluations under field conditions to assess their effectiveness on a commercial scale. Combined use of soil solarization and diverse amendments has been examined under field conditions by Yildiz and Benlioglu (2010). Results indicate that olive trees undergoing solarization alone or solarization plus amendment with olive processing waste showed disease recovery and symptom remission. Saremi et al. (2010) have also provided new information about the efficacy of soil solarization to reduce the inoculum density of the pathogen in olive and pistachio orchards. Reports on biological control approaches of Verticillium wilt of olive have deserved attention as well,

163 although the most recent published information is either preliminary or with very limited success. Thus, Aranda et al. (2011) have explored the potential of bacterial communities residing in the rhizosphere and endosphere of wild olive trees ( $O$. europaea L. subsp. europaea var. sylvestris). Their results indicate that both niches are important reservoirs of bacteria (mainly Bacillus spp., Pseudomonas spp., and

168 Paenibacillus spp.) showing in vitro antagonism against the defoliating pathotype of $V$. dahliae. But their effectiveness in planta still needs to be verified. The effect of 
170 arbuscular mycorrhizal fungi (Glomus intraradices alone or in combination with $G$. 171 mosseae) on growth and development of different olive cultivars was examined in 172 saline water-irrigated orchards under arid conditions and in the presence of $V$. dahliae 173 (Kapulnik et al. 2010). Setting aside the positive results obtained on transplant growth 174 and adaptation to arid areas after mycorrhization at the nursery, mycorrhizal fungi 175 colonization did not appear to improve tolerance of cultivars Picual (highly susceptible) 176 or Barnea (relatively tolerant) to V. dahliae. Finally, Bubici and Cirulli (2011) have 177 elegantly demonstrated that grafting of susceptible olive cultivars onto resistant 178 rootstocks of cultivar Frantoio provides very good control of Verticillium wilt caused 179 by the defoliating pathotype under specific conditions (root-dipping inoculation of the 180 pathogen and greenhouse incubation). The authors suggest that resistance in 'Frantoio' 181 plants takes place mainly in roots, involving biochemical mechanisms rather than 182 structural barriers.

183 We trust that addition of above-mentioned, totally-unintentional oversights and 184 hot-off-the-press studies, whose number has increased rapidly during the last few 185 months, will serve to complete and improve our contribution. The more research efforts 186 performed worldwide the better to properly understand and effectively face this 187 threatening disease.

\section{Acknowldegments}

We thank Drs. Jelena Latinovic, M. Laura Otero, Mónica Roca and Javad Sanei for kindly informing us of research reports and activities on Verticillium wilt of olive in their countries. We are grateful to Prof. Krishna Subbarao and Prof. Walter J Kaiser for their suggestions to improve the manuscript. Research on Verticillium wilt of olive by authors supported by grants AGL2007-65766, AGL2009-07275 and AGL2011-30137

196 (Spanish Ministerio de Ciencia e Innovación, cofinanced by FEDER of the EU), P07-

197 CVI-02624 and P08-AGR-03635 (Junta de Andalucía, Spain), and FEDERINIA RFP2009-00008-C02-01. 
206 Alfano G, Lustrato G, Lima G, Vitullo D, Ranalli G (2011) Characterization of 207 composted olive mill wastes to predict potential plant disease suppressiveness. Biol 208 Control 58:199-207

209

210 Aranda S, Montes-Borrego M, Jiménez-Díaz RM, Landa BB (2011) Microbial

211 communities associated with the root system of wild olives (Olea europaea L. subsp 212 europaea var. sylvestris) are good reservoirs of bacteria with antagonistic potential 213 against Verticillium dahliae. Plant Soil 343:329-345

214

215 Arslan M, Dervis S (2010) Antifungal activity of essential oils against three vegetative216 compatibility groups of Verticillium dahliae. World J Microbiol Biotechnol 26:1813$217 \quad 1821$

219 Berbegal M, Garzón CD, Ortega A, Armengol J, Jiménez-Díaz RM, Jiménez-Gasco 220 MM (2011) Development and application of new molecular markers for analysis of genetic diversity in Verticillium dahliae populatons. Plant Pathol 60:86-877

Bubici G, Cirulli M (2011) Control of Verticillium wilt of olive by resistant rootstocks. Plant Soil (in press) DOI 10.1007/s11104-011-1002-9

Docampo DM, Vázquez AA, Laguna IG (1981) Verticillium dahliae Kleb. causal de la paralisis del olivo en el área olivera centro oeste Argentina. Rev Invest Agropecuarias XVI(2):197-204 (in Spanish)

Erten L, Yildiz M (2011) Screening for resistance of Turkish olive cultivars and clonal rootstocks to Verticillium wilt. Phytoparasitica 39:83-92

Jiménez-Díaz RM, Olivares-García C, Landa BB, Jiménez-Gasco MM, Navas-Cortés 234 JA (2011) Region-wide analysis of genetic diversity in Verticillium dahliae populations infecting olive in southern Spain and agricultural factors influencing the distribution and prevalence of vegetative compatibility groups and pathotypes. Phytopathology 101:304- 
239 Kapulnik Y, Tsror L, Zipori I, Hazanovsky M, Wininger S, Dag A (2010) Effect of MF

240 application on growth, productivity and susceptibility to Verticillium wilt of olives grown under desert conditions. Symbiosis 52:103-111

Klosterman SJ, Subbarao KV, Kang SC, Veronese P, Gold SE, Thomma BPHJ, Chen ZH, Henrissat B, Lee YH, Park J, García-Pedrajas MD, Barbara DJ, Anchieta A, de Jonge R, Santhanam P, Maruthachalam K, Atallah Z, Amyotte SG, Paz Z, Inderbitzin P, Hayes RJ, Heiman DI, Young S, Zeng QD, Engels R, Galagan J, Cuomo CA, Dobinson KF, Ma LJ (2011) Comparative genomics yields insights into niche adaptation of plant vascular wilt pathogens. PLOS Pathogens 7:e1002137

Laouane H, Lazrek HB, Sedra MH (2011) Synthesis and toxicity evaluation of cinnamyl acetate: a new phytotoxin produced by a strain of Verticillium dahliae pathogenic on olive tree. Intl J Agr Biol 13:444-446

Latinovic J, Vucinic Z (2010) First report of Verticillium dahliae on olives in Montenegro. Petria 20:253

Lo Giudice V, Raudino F, di San Lio RM, Cacciola SO, Faedda R, Pane A (2010) First report of a decline and wilt of young olive trees caused by simultaneous infections of Verticillium dahliae and Phytophthora palmivora in Sicily. Plant Dis 94:1372-1373

López-Escudero FJ, Mercado-Blanco J (2011) Verticillium wilt of olive: a case study to implement an integrated strategy to control a soil-borne pathogen. Plant Soil 344:1-50

López-Escudero FJ, Mercado-Blanco J, Roca JM, Valverde-Corredor A, Blanco-López MA (2010) Verticillium wilt of olive in the Guadalquivir Valley (southern Spain): relations with some agronomical factors and spread of Verticillium dahliae. Phytopathol Med 49:370-380

268

269 Maruthachalam K, Atallah ZK, Vallad GE, Klosterman SJ, Hayes RJ, Davis RM, 270 Subbarao KV (2010) Molecular variation among isolates of Verticillium dahliae and 
271 polymerase chain reaction-based differentiation of races. Phytopathology 100:12222721230

273

274 Nicolini JC, Traversi (1950) Observaciones sobre una nueva enfermedad del olivo en 275 Argentina. IDIA 32:8-11 (in Spanish)

276

277 Rodríguez E, García-Garrido JM, García PA, Campos M (2011) Implications of plant 278 material origin, land use history and soil properties in the incidence of verticillium wilt 279 in olive groves. J Plant Pathol 93:111-118

280

281

Sanei SJ, Razavi SE, Okhovvat SM, Pahlavani MH (2010) Verticillium Wilts. Peik-e282 Reihan Publication (in Farsi)

283

284 Saremi H, Amiri ME, Mirabolfathi M (2010) Application of soil solarization for 285 controlling soilborne fungal pathogens in newly established pistachio and olive 286 orchards. Int J Fruit Sci 10:143-156

287

288

Sesli M, Onan E, Oden S, Yener H, Yegenoglu ED (2010) Resistance of olive cultivars 289 to Verticillium dahliae. Sci Res Essays 5:1561-1565

290

291 Tjamos EC (1993) Prospects and strategies in controlling Verticillium wilt of olive. Bull 292 OEPP/EPPO Bull 23:505-512

294 Tjamos EC, Jiménez-Díaz RM (1998) Management of disease. In: Hiemstra JA, Harris 295 DC (eds) A compendium of Verticillium wilts in tree species. Ponsen and Looijen, 296 Wageningen, pp 55-57

298 Trapero C, Roca LF, Alcántara E, López-Escudero FJ (2011) Colonization of olive 299 inflorescences by Verticillium dahliae and its significance for pathogen spread. J 300 Phytopathol 159:638-640

302 Yangui T, Sayadi S, Gargoubi A, Dhouib A (2010) Fungicidal effect of hydroxytyrosol303 rich preparations from olive mill wastewater against Verticillium dahliae. Crop 304 Protection 29:1208-1213 
306 Yildiz A, Benlioglu S, (2010) Effects of soil solarization and some amendments to 307 control verticillium wilt in established olive orchards. Afr J Biotechnol 9:6660-6665 308 